Preprint

UCRL-JC-139493

\title{
Endoscopic Subsurface Imaging in tissues
}

S. G. Demos, M. Staggs, H. B. Radousky

This article was submitted to Photonics West 2001 Advanced Technical Program, San Jose, CA, January 20-26, 2001

\section{February 12, 2001}

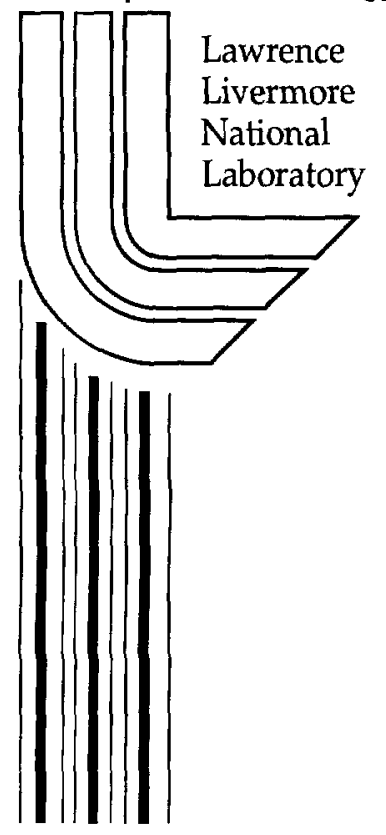




\section{DISCLAIMER}

This document was prepared as an account of work sponsored by an agency of the United States Government. Neither the United States Government nor the University of California nor any of their employees, makes any warranty, express or implied, or assumes any legal liability or responsibility for the accuracy, completeness, or usefulness of any information, apparatus, product, or process disclosed, or represents that its use would not infringe privately owned rights. Reference herein to any specific commercial product, process, or service by trade name, trademark, manufacturer, or otherwise, does not necessarily constitute or imply its endorsement, recommendation, or favoring by the United States Government or the University of California. The views and opinions of authors expressed herein do not necessarily state or reflect those of the United States Government or the University of California, and shall not be used for advertising or product endorsement purposes.

This is a preprint of a paper intended for publication in a journal or proceedings. Since changes may be made before publication, this preprint is made available with the understanding that it will not be cited or reproduced without the permission of the author.

This work was performed under the auspices of the United States Department of Energy by the University of California, Lawrence Livermore National Laboratory under contract No. W-7405-Eng-48.

This report has been reproduced directly from the best available copy.

Available electronically at http://www.doc.gov/bridge

Available for a processing fee to U.S. Department of Energy

And its contractors in paper from

U.S. Department of Energy

Office of Scientific and Technical Information

$$
\text { P.O. Box } 62
$$

Oak Ridge, TN 37831-0062

Telephone: (865) 576-8401

Facsimile: (865) 576-5728

E-mail: reports@adonis.osti.gov

Available for the sale to the public from

U.S. Department of Commerce

National Technical Information Service

5285 Port Royal Road

Springfield, VA 22161

Telephone: (800) 553-6847

Facsimile: (703) 605-6900

E-mail: orders@ntis.fedworld.gov

Online ordering: http://www.ntis.gov/ordering.htm

\section{OR}

Lawrence Livermore National Laboratory

Technical Information Department's Digital Library

http://www.llnl.gov/tid/Library.html 


\title{
Endoscopic subsurface imaging in tissues
}

\author{
S. G. Demos, M. Staggs, H. B. Radousky \\ Lawrence Livermore National Laboratory, PO Box 808, L-411, Livermore, CA 94551.
}

\begin{abstract}
The objective of this work is to develop endoscopic subsurface optical imaging technology that will be able to image different tissue components located underneath the surface of the tissue at an imaging depth of up to 1 centimeter. This effort is based on the utilization of existing technology and components developed for medical endoscopes with the incorporation of the appropriate modifications to implement the spectral and polarization difference imaging technique. This subsurface imaging technique employs polarization and spectral light discrimination in combination with image processing to remove a large portion of the image information from the outer layers of the tissue which leads to enhancement of the contrast and image quality of subsurface tissue structures.
\end{abstract}

Key words: Polarization, Tissues, Backscattering, Subsurface imaging.

\section{INTRODUCTION}

Endoscopes are imaging modalities that are used to attain images of human organs such as bladder, colon, gastrointestinal track and bronchus for diagnostic purposes. Similar medical imaging modalities are also used in laparoscopic surgical procedures for viewing the internal parts of the human body. Endoscopes operate under white light illumination to provide color images via a video system that allow for the identification of alterations from normal tissue conditions through changes in color and blood concentrations as well as the observation of structural changes. Because the penetration depth of visible light through tissue is small, the information obtained using optical endoscopes represent only the superficial layers of the tissue or organ under investigation.

The spectral polarization difference imaging technique (SPDI). was recently introduced as a subsurface imaging method that can be used to highlight differences in absorption or scattering due to the presence of different types of tissue $[1,2]$. The SPDI technique utilizes the wavelength dependence of the mean visit depth of photons inside a tissue sample before they emerge in the backscattered direction. Polarization filtering is used to discriminate against reflected photons from the superficial tissue layers. In addition, this technique involves subtraction of the perpendicular polarization image components obtained under polarized illumination at different wavelengths following appropriate adjustment of the time of exposure in order to normalize the recorded image intensity arising from photons backscattered from the outer tissue layers. This operation leads to a new image arising from photons that propagated deeper into the tissue that exist in larger numbers in the image obtained using the longer illumination wavelength. The utilization of different illuminating wavelengths allows for imaging using photons that reached different penetration depths inside the host tissue: With gradual change of the illuminating wavelengths one can effectively image structures in different depth zones depending on the photon penetration depth of the pair of illumination wavelengths utilized to record the original images. A large (small) difference in the two wavelengths gives rise to a wider (narrower) depth zone.

In this work we examine the feasibility to develop endoscopic subsurface imaging technology by incorporating the spectral polarization difference imaging technique into different types of existing endoscopes. Such an imaging system should be able to provide information of different tissue structures on the surface and below the surface at different depth zones. The experiments were carried out using a commercially available endoscope. Subsurface images of tissue components located below the surface were obtained using animal tissues as model media.

'Correspondence: Email: Demosl@llnL_gov: Telephone: 925423 3388; Fax: 9254232463 


\section{EXPERIMENTAL PROCEDURE}

The experimental setup is shown in fig. 1a. A low-power, white-light source coupled to a fiber bundle is used to deliver the illumination light into the sample. A narrow band interference filter is used to achieve illumination of the sample with light of a particular wavelength. A polarizer positioned at the output of the fiber ensured polarized illumination of the sample. Images of the sample in the backscattering geometry were captured using a commercially available endoscope lens (Olympus, A1931) followed by image relaying optics and a liquid nitrogen cooled CCD detector. This lens is used in cystoscopes for imaging of the bladder. A second polarizer is positioned in front of the endoscope lens with its polarization orientation perpendicular to that of the first polarizer in order to record only the perpendicular polarization image component. The depth of focus of the lens was sufficient to allow capture of images of the interesting object located below the surface of the sample.

Fig. 1b shows a conventional image (converted to gray-scale) of a human bladder from a cancer patient using an identical cystoscope to that depicted in fig. 1a. Brighter features in these images arise from cancer lesions located on the surface of the bladder tissue. For this investigation, the sample used to demonstrate this endoscopic subsurface imaging method was a structure prepared using chicken breast tissue as a model medium.
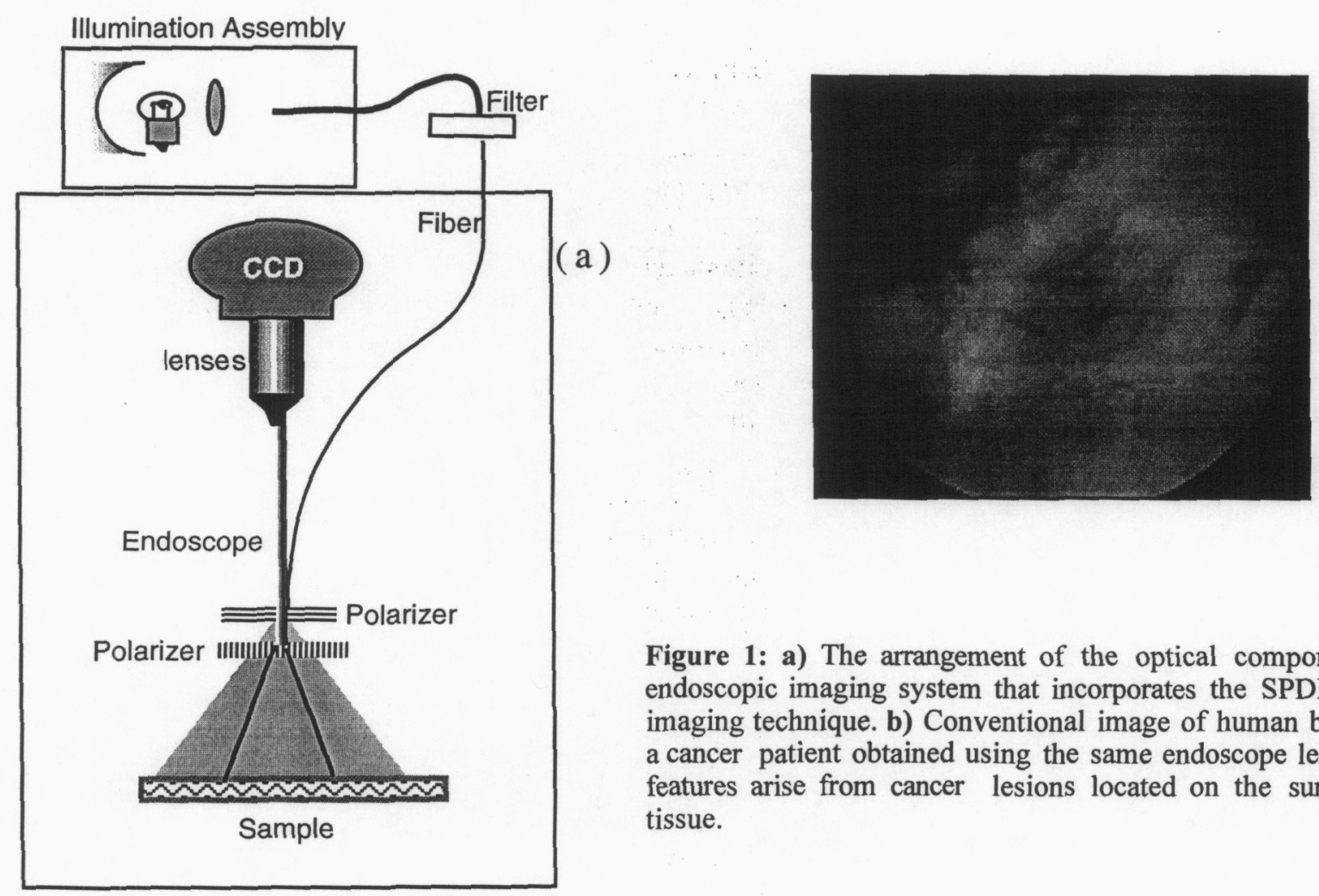

Figure 1: a) The arrangement of the optical components of an endoscopic imaging system that incorporates the SPDI subsurface imaging technique. b) Conventional image of human bladder from a cancer patient obtained using the same endoscope lens. Brighter features arise from cancer lesions located on the surface of the tissue.

\section{EXPERIMENTAL RESULTS}

Figures $2 \mathrm{a}$ and $2 \mathrm{~b}$ show images of a $2-\mathrm{cm}$ thick chicken breast tissue sample under $690-\mathrm{nm}$ and $820-\mathrm{nm}$ illumination. The sample was prepared using three chicken breast tissue layers. The top layer was $0.5-\mathrm{cm}$ thick and consisted of homogenous breast tissue. The second layer was also $0.5-\mathrm{cm}$ in thickness, but it contained a tendon lesion on its surface. In the middle of the surface of the third, $1-\mathrm{cm}$ thick, breast tissue layer, an $\approx 4-\mathrm{mm}$ in diameter, 2-mm thick fat lesion was positioned and sandwiched between the second and third breast tissue layers. The three layer, $2-\mathrm{cm}$ thick, sample was placed between two glass slides and slightly compressed to a uniform thickness. The 

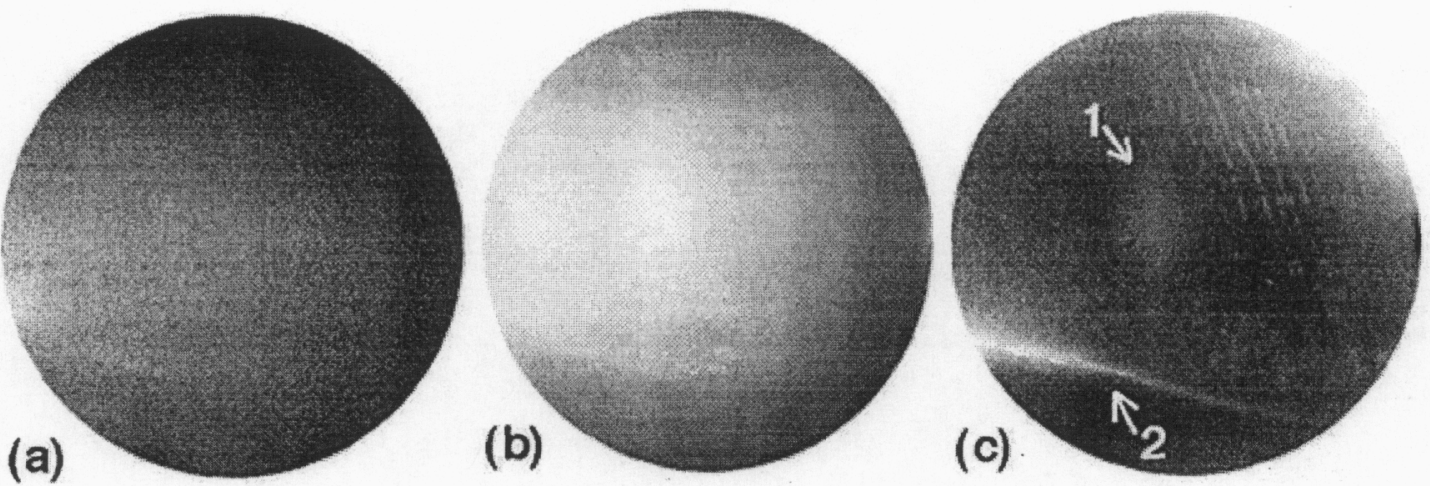

Figure 2: Images of a chicken breast tissue sample that contains fat ("1") and tendon ("2") tissue lesions located 1$\mathrm{cm}$ and $0.5-\mathrm{cm}$, respectively, below the surface of the sample. The perpendicular polarization image components under $690-\mathrm{nm}$ (a) and $820-\mathrm{nm}$ (b) illumination. (c) The SPDI image obtained using 970-nm and 820-nm illumination.

SPDI image obtained using $970-\mathrm{nm}$ and $820-\mathrm{nm}$ illumination is shown in figure 2c. Two features observed in this image denoted as " 1 " and " 2 " show the fat tissue ("1") and tendon tissue ("2") lesions located 1-cm and 0.5-cm, respectively, below the surface of the sample. Figures $2 a$ and $2 b$ demonstrate that these features are not visible or difficult to be identified when direct images are recorded even when polarization filtering (to reject the less scattered photon on the outer tissue layers) or NIR illumination wavelengths (to reach larger photon propagation depths) are used. Using white light illumination and color video imaging (typical operation of endoscopes), these two tissue lesions located below the surface are not visible and it would be impossible for the operator to detect. These results demonstrate that the application of the SPDI technique for endoscopic imaging is possible.

\section{DISCUSSION}

The main difficulty for the incorporation of the SPDI technique into endoscopic imaging is the requirement for polarization sensitive image acquisition. The illumination needs to be polarized while the cross-polarized image component must be recorded and used in the inter-image operation leading to the SPDI image. To the best of our knowledge, there is no commercially available endoscope at the present time that offers polarization preserving optics. Therefore, the illumination needs to be delivered through a separate fiber than the optical element used for imaging while polarizers located at the tip of the fiber and the input of the endoscope will ensure proper polarized illumination and image acquisition. In a different configuration, a polarization preserving fiber may be used to deliver the illumination light. The diameter of the illumination fiber should be smaller than that of the working channels of the endoscope which can be used in order to deliver the polarized, multicolor illumination into the tissue. Finally, the imaging lens of the endoscope may by composed of an image-collection fiber-bundle made by polarization preserving fibers. In this case, the analyzer can be located at the end of the endoscope (in front of the $\mathrm{CCD})$.

The presence of characteristic optical "signatures" of various tissue components is key to the success of any photonic imaging modality for biomedical applications. These optical "signatures" may arise from differences in the cellular level (size of the cells and nucleus, density and cell makeup). The differences between cancer tissue when compared to normal tissue offers the promise for the development of optical imaging technology particularly suitable for cancer detection [3-4]. Except for skin cancer, all the other types of cancer occur inside the body and are very difficult to be detected at early stages. A large percentage of these cancers occur inside the body and can be reached 
and viewed using various types of endoscopes. Stomach, cervix, uterus, colon, rectum, bronchus and bladder cancers could be detected at early stages and can be best treated if a suitable minimally invasive endoscopic screening system existed. In addition, such an endoscopic screening system could assist in monitoring the development of a cancerous tumor(s) for an assessment of the success of the treatment of the patient with chemotherapy or any other method.

The images obtained using the approaches discussed in this work will be able to provide information regarding the presence of different tissue structures on the surface and below the surface. The utilization of this technology incorporated into different types of existing endoscopes with the appropriate modifications can be realized using low cost off-the-self components. This technology may also find applications in other areas of basic and clinical research as well as in clinical diagnostics. If appropriate optical "signature(s)" exists, this method could be useful for the diagnosis of clinical disease, early detection/screening, for identifying the presence of toxicant or drugs at specific target sites in the body, for determining the concentrations of these agents on the target sites of interest for monitoring individual therapies, for assessing pharmacokinetic and pharmacodynamics in basic and clinical research and in forensic analysis.

\section{CONCLUSION}

An endoscopic imaging system for surface and subsurface imaging for clinical applications may only require small modifications of existing endoscopes to provide inexpensive technology which the medical personnel is already familiar with. As a result, this technology can become an easily accessible screening and diagnostic tool to the medical community due to the anticipated low cost of acquisition and operation and the limited expertise and training required. This imaging technology may find application in the early detection/screening of cancer, in providing minimally invasive monitoring of the tumor's response to various stages of treatments and in assisting during surgery by providing information on the depth of penetration of the tumor. In laparoscopic surgical applications, this technology may be used to provide information regarding the presence of tissue structures that need to be preserved such as veins, arteries and nerves.

\section{ACKNOWLEDGMENTS}

This publication was made possible by funds received from the Cancer Research Fund, under Interagency Agreement \#97-12013 (University of. California, Davis contract \#98-00924V) with the Department of Health Services, Cancer Research Section. This work was performed under the auspices of the U.S. Department of Energy by the University of California, Lawrence Livermore National Laboratory under Contract No. W-7405-Eng-48.

\section{REFERENCES}

1. S. G. Demos and R.R. Alfano, "Optical Polarization Imaging" Applied Optics, 36, 150-155, 1997.

2. S. G. Demos, H. B. Radousky and R. R. Alfano, "Deep Subsurface Imaging in Tissues using Spectral and Polarization Filtering", Optics Express, 7, 23-28, 2000.

3. K. A. Kang, B. Chance, S. Zhao, S. Srinivasan, E. Patterson, and R. Troupin, "Breast Tumor Characterization Using Near-Infrared Spectroscopy." Photon Migration and Imaging in Random Media and Tissues, Ed. by B. Chance and R. R. Alfano, SPIE 1888: 487-499, 1993 and references therein.

4. J.R. Mourant, Bigio I.J., Boyer J., Conn R.L., Conn R.L., Johnson T., Shimada T, "Spectroscopic Diagnosis of Bladder Cancer with Elastic Light Scattering”, Lasers Surgery and Medicine, 17, 350-357, 1995. 